\title{
THE ROLE OF ASPERGILLI AND PENICILLIA IN MYCOTOXIN CONTAMINATION OF MAIZE IN HUNGARY
}

\author{
B. Tóth ${ }^{1}$, O. TöröK ${ }^{1}$, É. Kótai ${ }^{1}$, M. VARGA $^{1}$, É$^{\text {E. TOldiné Tóth }}{ }^{1}$, X. PÁlfi ${ }^{1}$, \\ E. HÁfra ${ }^{1,2}$, J. VARGA $^{2}$, J. TÉREN $^{3}$, Á. MESTERHÁZY $^{1}$ \\ ${ }^{1}$ Cereal Research Nonprofit Ltd., Szeged, Hungary; beata.toth@gabonakutato.hu \\ ${ }^{2}$ University of Szeged, Faculty of Science and Informatics, Department of \\ Microbiology, Szeged, Hungary \\ ${ }^{3}$ University of Szeged, Faculty of Engineering, Szeged, Hungary
}

Running title: Mycotoxin contamination of maize

Aspergillus and Penicillium species and their mycotoxins including aflatoxins, ochratoxins, fumonisins and patulin are frequently encountered on cereal products. We investigated the occurrence of these species and their mycotoxins on maize in Hungary in 2 consecutive years after harvest. Surface-sterilized cereal seeds were placed on selective media, and the isolated fungal strains were identified using morphological methods. $81.94 \%$ and $14.33 \%$ of the samples were found to be contaminated with potentially toxigenic isolates in 2010 and 2011, respectively. Species identifications of selected isolates have been carried out using sequencebased methods. Several Aspergillus flavus isolates were identified, which are potential aflatoxin producers. Besides, other mycotoxin producer species were also isolated, including black Aspergilli which potentially produce ochratoxins and fumonisins, and A. clavatus, which produces patulin. In 2010 large number of 
Penicillium species occurred in the samples, producing a wide range of mycotoxins. The mycotoxin content of the samples was analyzed using ELISA and HPLC techniques. Aflatoxins were not detected in any of the samples, while ochratoxins and fumonisins were successfully identified in some of the maize seeds.

Keywords: maize, Aspergillus flavus, aflatoxins, fumonisins, ochratoxins, Penicillium, sequence-based identification, climate change

\section{Introduction}

Aspergillus and Penicillium are among the economically most important fungal genera. Aspergillus isolates are used for the production of soy sauce, several organic acids and enzymes, and biologically active metabolites such as lovastatin, while Penicillia are used in the pharmaceutical industry to produce penicillin, and in the food industry for the production of various cheeses and salami. Although not considered to be major causes of plant disease, both Aspergillus and Penicillium species may be responsible for several disorders in various plants (Varga et al., 2004). The most notorious plant pathogens are Aspergillus niger, A. flavus and Penicillium expansum which may cause various plant diseases. In contrast with specialized plant pathogens such as powdery mildews, rusts or most Fusarium species, these species are opportunistic pathogens without host specialization as proved in A. flavus (Varga et al., 2004).

The most important aspect of food spoilage caused by these organisms is the formation of mycotoxins, which may have harmful effects on human and 
animal health. Several mycotoxins have been identified which may contaminate foods including various agricultural products like cereals, fruits and vegetables, the economically most important of which are aflatoxins, ochratoxins and fumonisins. EU limits exist for all of these Aspergillus/Penicillium mycotoxins in cereals. In the case of aflatoxins, $4 \mu \mathrm{g} / \mathrm{kg}$ total aflatoxin content is allowed in all cereal products. Regarding ochratoxins, $5 \mu \mathrm{g} / \mathrm{kg}$ is the limit for unprocessed cereals, and $3 \mu \mathrm{g} / \mathrm{kg}$ for cereal products intended for direct human consumption. In the case fumonisins, $4000 \mu \mathrm{g} / \mathrm{kg}$ is the limit for unprocessed maize, and 200 $\mu \mathrm{g} / \mathrm{kg}$ for foods intended for infants and children.

Although Fusarium toxins including trichothecenes, zearalenone and fumonisins are treated as the most important in cereals in areas with temperate climate, mycotoxins produced by Aspergilli and Penicillia are also frequently identified in different cereal products. In Croatia aflatoxin producing isolates from maize and flour were identified (Halt, 1994, Halt et al., 2004). Serious A. flavus field infection and aflatoxin contamination was detected in 2003 in Northern Italy (Giorni et al., 2007). In Romania, although aflatoxins were not detected in cereal samples in 1998 (Curtui et al., 1998), about 30\% of the cereal samples examined were found to be contaminated between 2002 and 2004 (Tabuc et al., 2009). In $20 \%$ of these samples, the aflatoxin levels exceeded the EU limits. More recently, Borbély et al. (2010) have examined mycotoxin levels in cereal samples and mixed feed samples collected in eastern Hungary, and detected $\mathrm{AFB}_{1}$ levels above the EU limit in some of the samples. Besides, Dobolyi et al. (2011) have recently identified aflatoxin producing A. flavus isolates from maize kernel collected in various parts of Hungary. 
Ochratoxin A has also been frequently identified in cereal samples in several European countries including Hungary, Croatia, Spain and Portugal. According to a recent survey of mycotoxins worldwide, aflatoxins have been detected in $6 \%$ of cereal samples collected in Central Europe, while fumonisins and ochratoxins were found in $29 \%$ and $41 \%$ of the samples, respectively (http://www.biomin.net/mycoreport/mtsurvey.html). Ochratoxins are produced by P. verrucosum on cereals under colder climatic conditions (e.g. in Northern parts of Europe; Lund and Frisvad, 2003), while Aspergilli dominate in the tropical and subtropical regions (Magnoli et al., 2007).

Regarding fumonisins, maize products are frequently contaminated by them. The principal producing organisms are Fusarium species, although black Aspergilli also frequently occur on maize kernels. Black Aspergilli are suspected to be responsible for fumonisin contamination of several agricultural products including grapes, onions and figs (Varga et al., 2010, 2012).

These observations led us to examine the occurrence of mycotoxin producing Aspergillus and Penicillium species in Hungarian maize. The questions planned to be answered were: 1. what is the frequency of occurrence of aflatoxigenic Aspergilli in Hungarian maize; 2. which species is responsible for OTA contamination of maize in Hungary; and 3. whether black Aspergilli contribute to the overall fumonisin contamination of maize.

\section{Materials and methods}

\section{Sample collection}


The samples were collected in 9 and 10 maize growing regions in 2010 and 2011, respectively. The samples were surface sterilized using ethanol, and plated onto dichloran rose bengal (DRBC) media (King et al., 1979). Plates were incubated at $25^{\circ} \mathrm{C}$ in darkness and monitored periodically for characteristic mycelium growing from the kernels. Outgrowing mycelia were purified and transferred to malt extract agar (MEA) media. Isolates were subcultured as single conidia on MEA, Czapek-yeast extract agar (CYA) and potato dextrose agar (PDA) plates (Samson et al., 2004).

\section{Identification of fungal isolates}

Morphological identification of Aspergilli/Penicillia isolated from maize grains have been done according to standard textbooks and monographs (Raper and Fennell, 1965, Samson et al., 2004, 2010). For sequence based identification, the cultures used for the molecular studies were grown on malt peptone (MP) broth for 2 days, and DNA was extracted from the mycelia using the Masterpure ${ }^{\mathrm{TM}}$ yeast DNA purification kit (Epicentre Biotechnol.) according to the instructions of the manufacturer. Part of the calmodulin gene was amplified and sequenced as described previously (Pildain et al., 2008). Calmodulin sequences were compared using nucleotide-nucleotide BLAST (blastn) with default settings (http://blast.ncbi.nlm.nih.gov; Altschul et al., 1990) to the Genbank database, and to our own sequence database. Species identification was determined from the lowest expect value of the BLAST output.

\section{Mycotoxin content analysis}


The aflatoxin and fumonisin content of the maize samples were detected by HPLC-MS technique. The toxins were extracted with a mixture of methanol:distilled water (70:30) in a vertical shaker for $2.5 \mathrm{~h}$. The membranefiltered extracts $\left(\begin{array}{ll}1 & \mu l\end{array}\right)$ were directly examined by high-performance liquid chromatography (HP 1090 HPLC) coupled with electrospray ionisation tandem mass spectrometry (Varian 500-MS) operating in positive ion mode. The components were separated with the use of a gradient of formic acid-methanol and distilled water on a reversed phase column (Polaris C18-A, $150 \times 3 \mathrm{~mm} \times$ $3 \mu \mathrm{m})$. Aflatoxins were differentiated with the use of characteristic fragment ions $\left(\mathrm{AFB}_{1}: \mathrm{m} / \mathrm{z} 313.0>285.1\right.$, aflatoxin $\mathrm{B}_{2}: \mathrm{m} / \mathrm{z} 315.0>287.1$ ) produced by cleavage of the protonated molecule ion in MS/MS mode. In order to determine the quantity of the toxins external standard method was applied. The ochratoxin contents of selected samples from 2010 were determined with ELISA tests according to the instructions of the manufacturer (RIDASCREEN ${ }$, R-Biopharm AG, Darmstadt, Germany).

\section{Results}

In this study, we examined the occurrence of potential mycotoxin producing Aspergillus and Penicillium in maize in Hungary. The surface-sterilized cereal seeds were placed on selective media, and the isolated fungal strains were identified using morphological and sequence-based methods. The overall fungal contamination rate of the samples was $81.94 \%$ in 2010 , while only $14.33 \%$ of the samples were found to be contaminated in 2011 (Table 1). The lower contamination rate observed in 2011 is possibly due to the weather conditions. While the summer was rainy in 2010, it was dry and hot in 2011. Possibly due to 
the humid weather conditions, Penicillia were frequently isolated from the samples collected in 2010 , while this genus was virtually absent in the samples collected in 2011. However, Fusaria were present in the samples in both years.

The number of primary isolates of each sample was restricted upon the grounds of colony and microscopic features and only the diverging ones were maintained for further investigations. 340 and 90 isolates were recovered in 2010 and 2011, respectively. Among the examined samples, several isolates were found to be members of section Flavi of the genus Aspergillus based on colony morphology and microscopic features (Fig. 1). Although several Aspergillus species have been identified recently which are able to produce aflatoxins, $A$. flavus, A. parasiticus and A. nomius are the economically most important species regarding aflatoxin contamination of agricultural products (Varga et al., 2009). These species can readily be distinguished using sequence analysis of part of their $\beta$-tubulin or calmodulin genes (Varga et al., 2011). Species assignment of the isolates was carried out using partial sequence analysis of their calmodulin gene. All isolates assigned to section Flavi based on morphological features were found to belong to the A. flavus species based on sequence data.

Besides A. flavus, several other potential mycotoxin producers were identified in the samples. The patulin producer A. clavatus and black Aspergilli able to produce both ochratoxins and fumonisins were recovered from several samples (Fig. 1). Regarding Penicillia, several mycotoxin producers were identified (e.g. P. crustosum, $P$. brevicompactum, $P$. chrysogenum and $P$. viridicatum). Other mycotoxin producing genera including Fusarium species were also identified. Among Fusaria, F. verticillioides dominated, although other species ( $F$. graminearum, $F$. proliferatum, $F$. sporotrichioides, $F$. subglutinans) 
could also be identified in some samples. Other genera (Alternaria, Nigrospora, Epicoccum, Cladosporium) were found in smaller proportions (data not shown).

Aflatoxin and fumonisin content of the samples was analyzed using HPLC-MS. None of the samples were found to be contaminated by any of the aflatoxins $\left(B_{1}, B_{2}, G_{1}, G_{2}\right)$. Fumonisins $\left(B_{1}+B_{2}\right)$ were observed to be present in quantities exceeding the EU limit in samples collected in Pacsa $(4.66 \mathrm{mg} / \mathrm{kg})$, Kőszárhegy (10.15 mg/kg), Majs (5.13 mg/kg) and Szeged $(7.55 \mathrm{mg} / \mathrm{kg})$ in 2010. One sample collected in Bruck (Austria) was contaminated by $30.77 \mathrm{mg} / \mathrm{kg}$ fumonisins, which is more than seven times higher than the EU limit (4 mg/kg). Ochratoxin content of the samples collected in 2010 was analyzed by the ELISA technique. Among the analyzed 35 samples, ochratoxin content of 34 ones was well above the EU limit (data not shown). Confirmation of these results using HPLC analysis is in progress.

\section{Discussion}

During a survey of mycotoxin producing molds in Hungarian maize samples in 2010 and $2011,81.94 \%$ and $14.33 \%$ of the samples were found to be contaminated with potentially toxigenic isolates. Several Aspergillus flavus isolates were identified, which are potential aflatoxin producers. Besides, other mycotoxin producing species, including black Aspergilli which potentially produce ochratoxins and fumonisins, Penicillium species producing a range of mycotoxins, and Fusarium species have also been identified. Our data indicate that possibly black Aspergilli and Penicillia are responsible for ochratoxin contamination, while black Aspergilli have little role in fumonisin contamination 
of maize in Hungary. The most contaminated samples came from 2010, possibly due to the rainy, humid weather conditions. Samples came from 2011 were found to be infected less severely, but the Aspergillus infection was higher than in the previous year. We consider this situation as a potential risk regarding toxin contamination of Hungarian agricultural products, similarly to the recent observations in neighbouring countries. Examination of the mycotoxin producing abilities of the isolates is in progress. A thorough investigation of the mycobiota of other agricultural products also seems to be necessary to estimate the potential effects of climate change on the occurrence of mycotoxin producing species in Hungary.

\section{Acknowledgements}

This work was supported by OTKA grant Nos. K84122 and K84077, by the János Bolyai Research Scholarship of the Hungarian Academy of Sciences (B. Tóth), and by the Hungarian Maize Club. The project is co-financed by the European Union through the Hungary-Serbia IPA Cross-border Co-operation Programme (ToxFreeFeed, HU-SRB/1002/122/062). We thank R. A. Samson (CBS-KNAW Fungal Biodiversity Centre, Utrecht, Netherlands) for help in microscopy.

\section{Rerefences}

Altschul, S. F., Gish, W., Miller, W., Myers, E. W., Lipman, D. J. (1990): Basic local alignment search tool. J. Mol. Biol., 215, 403-410. 
Borbély, M., Sipos, P., Pelles, F., Győri, Z. (2010): Mycotoxin contamination in cereals. J. Agronom. Proc. Techn., 16, 96-98.

Curtui, V., Usleber, E., Dietrich, R., Lepschy, J., Märtlbauer, E. (1998): A survey on the occurrence of mycotoxins in wheat and maize from western Romania. Mycopathologia, 143, 97-103.

Dobolyi, C., Sebők, F., Varga, J., Kocsubé, S., Szigeti, G., Baranyi, N., Szécsi, Á., Lustyik, G., Micsinai, A., Tóth, B., Varga, M., Kriszt, B., Kukolya, J. (2011): Aflatoxin-termelö Aspergillus flavus törzsek előfordulása hazai kukorica szemtermésben. (Occurrence of aflatoxin producing Aspergillus flavus isolates on maize kernel in Hungary.) Növényvédelem, 47, 125-133.

Giorni, P., Magan, N., Pietri, A., Bertuzzi, T., Battilani, P. (2007): Studies on Aspergillus section Flavi isolated from maize in northern Italy. Int. J. Food Microbiol., 113, 330-338.

Halt, M. (1994): Aspergillus flavus and aflatoxin $\mathrm{B}_{1}$ in flour production. Eur. J. Epidem., 10, 555-558.

Halt, M., Klapec, T., Slibaric, D., Macura, M., Bacani, S. (2004): Fungal contamination of cookies and the raw materials for their production in Croatia. Czech J. Food Sci., 22, 95-98.

King, A. D. Jr., Hocking, A. D., Pitt, J. I. (1979): Dichloran-rose bengal medium for enumeration and isolation of molds from foods. Appl. Environ. Microbiol., 37, 959-964.

Lund, F., Frisvad, J. C. (2003): Penicillium verrucosum in wheat and barley indicates presence of ochratoxin A. J. Appl. Microbiol., 95, 1117-1123.

Magnoli, C. E., Astoreca, A. L., Chiacchiera, S. M., Dalcero, A. M. (2007): Occurrence of ochratoxin A and ochratoxigenic mycoflora in corn and corn 
based foods and feeds in some South American countries. Mycopathologia, 163, 249-260.

Pildain, M. B., Frisvad, J. C., Vaamonde, G., Cabral, D., Varga, J., Samson, R. A. (2008): Two novel aflatoxin-producing Aspergillus species from Argentinean peanuts. Int. J. Syst. Evol. Microbiol., 58, 725-735.

Raper, K. B., Fennell D. I. (1965): The genus Aspergillus. Williams and Wilkins, Baltimore.

Samson, R. A., Hoekstra, E. S., Frisvad, J. C. (2004): Introduction to Food-and Airborne Fungi. 7th edition. CBS Fungal Biodiversity, Center, Utrecht, Netherlands.

Samson, R. A., Houbraken, J., Thrane, U., Frisvad, J. C., Andersen, B. (2010): Food and indoor fungi. CBS-KNAW Fungal Biodiversity Centre, Utrecht.

Tabuc, C., Marin, D., Guerre, P., Sesan, T., Bailly, J.D. (2009): Molds and mycotoxin content of cereals in southeastern Romania. J. Food Protect. 72, $662-665$.

Varga, J., Frisvad, J. C., Samson, R. A. (2009): A reappraisal of fungi producing aflatoxins. World Mycotoxin J., 2, 263-277.

Varga, J., Frisvad, J. C., Samson, R. A. (2011): Two new aflatoxin producing species, and an overview of Aspergillus section Flavi. Stud. Mycol., 69, 5780.

Varga, J., Kocsubé, S., Suri, K., Szigeti, G., Szekeres, A., Varga, M., Tóth, B., Bartók, T. (2010): Fumonisin contamination and fumonisin producing black Aspergilli in dried vine fruits of different origin. Int. J. Food Microbiol., 143, $143-149$. 
Varga, J., Kocsubé, S., Szigeti, G., Man, V., Tóth, B., Vágvölgyi, C., Bartók, T. (2012): Black Aspergilli and fumonisin contamination in onions purchased in Hungary. Acta Aliment. (in press)

Varga, J., Tóth, B., Mesterházy, Á., Téren, J., Fazekas, B. (2004): Mycotoxigenic fungi and mycotoxins in foods and feeds in Hungary. In: Logrieco, A., Visconti, A. (eds.), An overview on toxigenic fungi and mycotoxins in Europe. Kluwer Academic Publishers, Amsterdam, pp. 123-139.
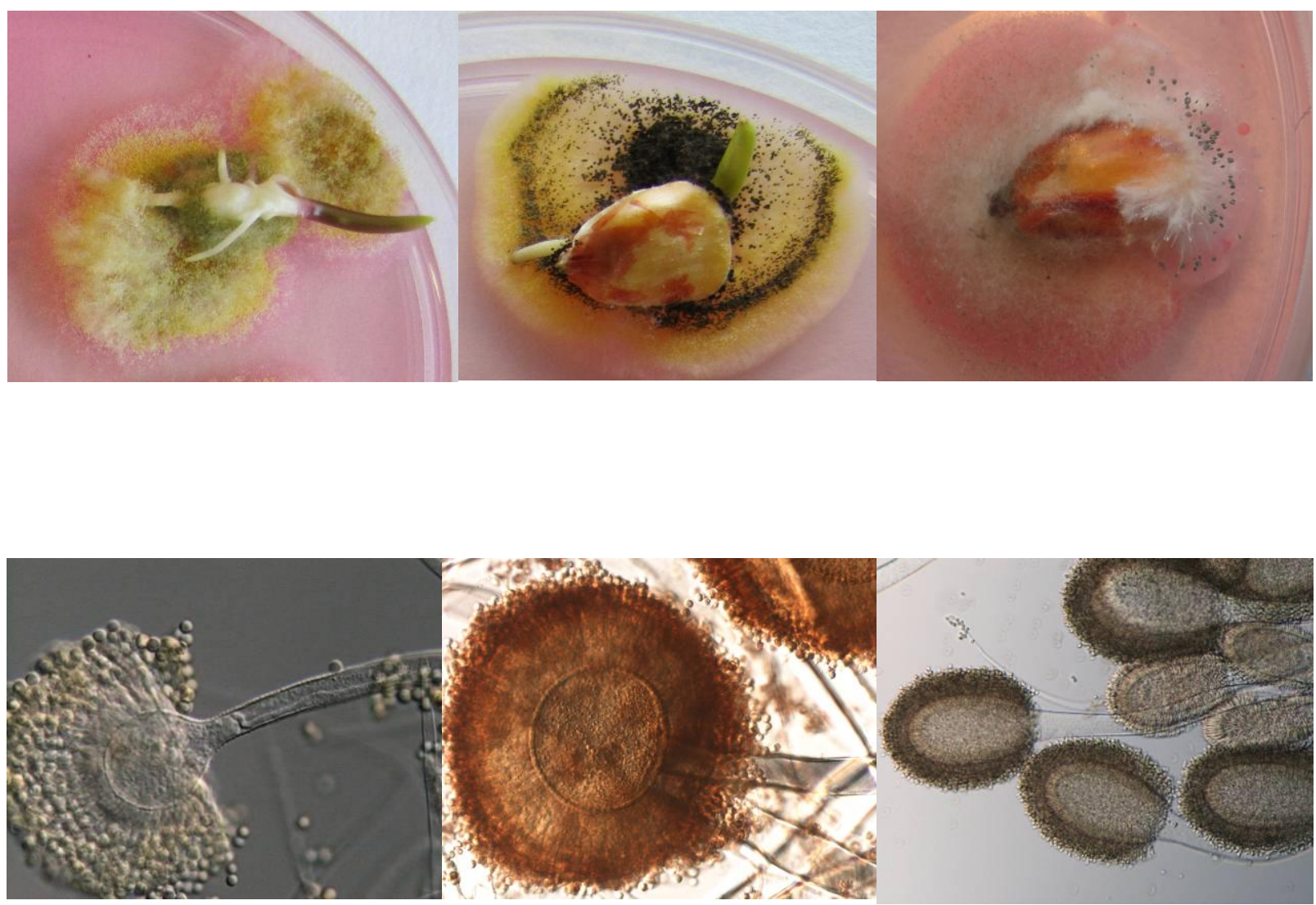

Fig. 1. Occurrence of Aspergillus flavus, A. niger and A. clavatus in maize seeds (top) and microscopic picture of their conidial heads (bottom) 
Table 1

Occurrence of mycotoxigenic fungi on maize in Hungary in 2010-2011

\begin{tabular}{|c|c|c|c|c|c|}
\hline \multirow[t]{2}{*}{ Year } & \multirow[t]{2}{*}{ Origin } & \multirow{2}{*}{$\begin{array}{c}\text { Infection of } \\
\text { grains, \% }\end{array}$} & \multicolumn{3}{|c|}{$\%$ of isolated fungal strains } \\
\hline & & & $\begin{array}{c}\text { Aspergillus } \\
\text { sp. }\end{array}$ & $\begin{array}{c}\text { Penicillium } \\
\text { sp. }\end{array}$ & Fusarium sp. \\
\hline \multirow[t]{10}{*}{2010} & Szeged & 80.83 & 2.06 & 26.80 & 71.13 \\
\hline & Hódmezővásárhely & 92.50 & 2.70 & 12.60 & 84.68 \\
\hline & Kétsoprony & 68.33 & 1.22 & 15.85 & 82.92 \\
\hline & Karcag & 80.00 & 5.21 & 10.42 & 84.37 \\
\hline & Köszárhegy & 75.83 & 1.09 & 21.99 & 75.84 \\
\hline & Pacsa & 96.66 & 0 & 62.93 & 37.07 \\
\hline & Iregszemcse & 87.50 & 4.76 & 1.90 & 93.33 \\
\hline & Majs & 83.33 & 0 & 30.00 & 70.00 \\
\hline & Mosonmagyaróvár & 72.50 & 1.15 & 65.52 & 33.33 \\
\hline & Average & 81.94 & 2.02 & 27.56 & 70.30 \\
\hline \multirow[t]{11}{*}{2011} & Szeged & 15.00 & 0 & 0 & 83.33 \\
\hline & Hódmezővásárhely & 1.66 & 0 & 0 & 0 \\
\hline & Jászboldogháza & 6.66 & 0 & 0 & 25.00 \\
\hline & Cegléd & 10.83 & 7.69 & 0 & 69.23 \\
\hline & Köszárhegy & 6.66 & 25.00 & 0 & 75.00 \\
\hline & Pacsa & 10.00 & 0 & 0 & 100 \\
\hline & Iregszemcse & 5.00 & 50.00 & 0 & 50.00 \\
\hline & Dalmand & 25.83 & 0 & 0 & 29.30 \\
\hline & Kaposvár & 25.00 & 0 & 0 & 93.33 \\
\hline & Bruck (Austria) & 36.66 & 0 & 0 & 77.27 \\
\hline & Average & 14.33 & 8.27 & 0.00 & 60.25 \\
\hline
\end{tabular}

